\title{
Kush - A Potential Biosorbent in the removal of Cd (II) and $\mathrm{Zn}$ (II) from aqueous solution
}

\author{
Jagjit Kour*, P.L. Homagai, M.R. Pokherel and K.N. Ghimire \\ Central Department of Chemistry, Tribhuvan University, Kirtipur, Kathmandu, Nepal \\ e-mail: jagjit_kour@hotmail.com
}

\begin{abstract}
The industrial discharge of heavy metals into waters' course is one of the major pollution problems affecting water quality. Therefore, they must be removed prior to their discharge into waste streams. An efficient and low-cost bioadsorbent has been investigated from Desmostachya bipinnata (Kush) by charring with concentrated sulphuric acid and functionalized with dimethylamine.It was characterised by SEM, FTIR and elemental analysis. The effect of $\mathrm{pH}$, initial concentration and contact time of the metal solution was monitered by batch method. The maximum adsorption capacities were determined for $\mathrm{Cd}$ and $\mathrm{Zn}$ at their optimum pH 6. The equilibrium data were analysed using Langmuir and Freundlich isotherm models. Langmuir isotherm model fitted well and the rate of adsorption followed the pseudo second order kinetic equation.
\end{abstract}

Keywords: Pollution, low-cost bioadsorbent, functionalization, elemental analysis, adsorption isotherm.

\section{Introduction}

Excessive release of heavy metals into the water bodies and environment due to industrial as well as human activities is a matter of global concern affecting water quality ${ }^{1,2,3}$. Heavy metals like $\mathrm{Cd}(\mathrm{II}) . \mathrm{Cr}(\mathrm{III}), \mathrm{Cu}(\mathrm{II}), \mathrm{Hg}$ (II), $\mathrm{Zn}$ (II) are discharged from numbers of industries like electroplating, dyes, textiles, tanneries, oil refineries, photpgraphy, battery, smelters, welding, pesticides and printing. ${ }^{3}$ Unlike organic wastes, heavy metals are non-biodegradable and their harmful effects in aquatic environment includes accumulation in living species and magnification throughout the food chain ${ }^{4,5,6}$. Therefore, they must be removed before descharge into waste streams. Many research works are in progress for the development of the cheaper and efficient treatment techniques to replace conventional treatment techniques such as ion exchange, membrane separation, and synthetic ion exchange resins. On the other hand, carbon adsorption is costly ${ }^{7,8,9}$. Biosorption is a low cost alternative method for the removal of heavy metals with very little amount of waste sludge as well as high degree of eficiency in decontaminating very dilute effulents ${ }^{10,11,12,13}$. The most commonly used agricultural wastes are renewable, cheap and their handling involves no additional risk ${ }^{19,20,21}$. In the present study, the

\section{${ }^{*}$ Corresponding author}


biomass of Kush plant is used as a biosorbent in the removal of heavy metals from aqueous solution. The aim of this study is to investigate the adsorption capacity and the kinetics of the $\mathrm{Cd}$ (II) and $\mathrm{Zn}$ (II) ions onto the Kush plant.

\section{Experimental Methods}

\section{Sample preparation}

The whole plant of Kush was used as biosorbent in this study. It was dried and cut into small pieces and washed with water and dried in sun and finally in an oven at $70{ }^{\circ} \mathrm{C}$ for $24 \mathrm{~h}$. The oven dried sample was grounded into fine powder using a grinding mechine. It was sieved through 212 micro meter siever. This sample is known as Raw Kush Powder (RKP).

About $100 \mathrm{~g}$ of RKP was charred with concentrated sulphuric acid and left overnight.The sample was throughly washed with distilled water till neutrality and dried in air followed by oven dry at $70^{\circ} \mathrm{C}$ for $24 \mathrm{~h}$. The charred Kush powder was treated with thionyl chloride in ice cold condition in presence of pyridine and heated on a water bath at $70{ }^{\circ} \mathrm{C}$ for one and half hour. The mixture was cooled and washed with distilled water till neutral $\mathrm{pH}$, then finally with propanol and left to air dry.This resulting biomaterial was taken in three necked round bottom flask along with dimethyl sulphoxide (DMSO), sodium carbonate and dimethylamine. The mixture was heated for $48 \mathrm{~h}$ at $70^{\circ} \mathrm{C}$, cooled, filtered and washed with $0.1 \mathrm{M}$ hydrochloric acid, then with water till neutral $\mathrm{pH}$ and finally with propanol. The biomaterial was air-dried and then oven dried for $24 \mathrm{~h}$ at $70^{\circ} \mathrm{C}$ and is rererred as Aminated Kush Powder (AKP).

\section{Preparation of solutions}

$1000 \mathrm{mg} / \mathrm{L}$ standard stock solution of Cd (II) and Zn (II) metal ions were prepared from their corresponding nitrate and sulphate salts by dissolving in deionised water. The standard stock solution was further diluted with $0.1 \mathrm{M}$ nitric acid in order to prepare the working solutions of desired concentration. 0.1M 2-[4-(2-hydroxyethyl)-1-piperazinyl] ethane sulphonic acid (HEPES) was added in all working solutions as buffering agent ${ }^{14,15,16}$.

\section{Effect of $p H$}

For $\mathrm{pH}$ study, $50 \mathrm{mg} / \mathrm{L}$ of $\mathrm{Cd}$ (II) and $\mathrm{Zn}$ (II) metal ions were taken and their $\mathrm{pH}$ were mantained from $\mathrm{pH} 1-7$, with the addition of $0.1 \mathrm{M}$ nitric acid and $0.1 \mathrm{M}$ sodium hydroxide where required.Then $25 \mathrm{mg}$ bio-material was taken in seven separate $50 \mathrm{ml}$ sample bottles with $20 \mathrm{ml}$ working solution of $\mathrm{Cd}$ (II) and $\mathrm{Zn}$ (II) metal ions each with different $\mathrm{pH}$ and shaken at room temperature at $150 \mathrm{rpm}$ for $24 \mathrm{~h}$ to attain equilibrium. After $24 \mathrm{~h}$, the solutions were filtered and their equilibrium concentrations were measured using ICP-AES (SPECTRO Analytical Instruments, Kleve, Germany).

\section{Effect of Metal ions concentration}

The adsorption of $\mathrm{Cd}$ (II) and $\mathrm{Zn}$ (II) metal ions were carried out taking metal ions of different concentration from $25 \mathrm{mg} / \mathrm{L}$ to $800 \mathrm{mg} / \mathrm{L}$ at their optimum $\mathrm{pH}$. The sample bottles were shaken at room temperature at $150 \mathrm{rpm}$ for $24 \mathrm{~h}$, then the solutions were filtered and equilibrium concentrations were measured using ICP-AES. The quantity of adsorbed metal ions 
was calculated from the decrease in metal ion concentration using the equation 1 . The results obtained were analysed using Langmuir Isotherm ${ }^{17}$.

$$
q_{e}=\left(C_{i}-C_{e}\right) \times \frac{V}{M}
$$

where, $\mathrm{q}_{\mathrm{e}}(\mathrm{mg} / \mathrm{g})$ is the amount of metal ions adsorbed by the biomaterial, $\mathrm{C}_{\mathrm{i}}(\mathrm{mg} / \mathrm{L})$ is the initial concentration of metal ions in aqueous solution, $\mathrm{C}_{\mathrm{e}}(\mathrm{mg} / \mathrm{L})$ is the concentration of metal ions in aquous solution at equilibrium, $\mathrm{V}(\mathrm{ml})$ is the initial volume of metal ions and $\mathrm{M}(\mathrm{g})$ is the weight of the biomaterial.

\section{Effect of contact time}

The effect of contact time on the adsorption of Cd (II) and $\mathrm{Zn}$ (II) metal ions were studied from 5 minutes to $6 \mathrm{~h}$. The experiment was carried out taking $25 \mathrm{mg}$ biomaterial along with 20 $\mathrm{ml}$ of respective metal ions solutions of $50 \mathrm{mg} / \mathrm{L}$ at their optimum $\mathrm{pH}$ in 14 different sample bottles. All the bottles were shaken in a shaker for the desired time interval and at the end of each contact time, the solution was filtered, then their concentrations were measured using ICPAES. The amount of metal adsorbed at time $(t)$ was calculated from the mass balance between initial concentration and concentration at time $(t)$ to analyse the adsorption rates of metal ions onto the biomaterial.

\section{Results and Discussion}

The surface morphology of Kush powder was analysed using scanning electron microscope before and after functionalization. The SEM image of raw and charred Kush powder show smooth and even surface as shown in figure (1a) and (1b). Formation of micropores on the surface of AKP was observed as shown in figure (1c). These changes of structure confirm the chemical modification on the surface of Aminated Kush ${ }^{18}$.

The functional groups present in the Kush powder were analysed with the help of diffuse reflectance infrared spectroscopy (DRIFT) (Harrick Scientific Corporation). The intense sharp adsorption peak at $3409 \mathrm{~cm}^{-1}$ in figure 4 indicates the $\mathrm{O}-\mathrm{H}$ stretching vibration due to inter and intramolecular hydrogen bonding of alcohols, phenols and carboxylic acids, indicating the presence of free hydroxyl groups on the biomaterial surface. Peaks at $2926 \mathrm{~cm}^{-1}$ corresponds to $\mathrm{C}-\mathrm{H}$ stretching vibration, $1736 \mathrm{~cm}^{-1}$ stretching vibration of bond due to non ionic carboxylic groups like $-\mathrm{COOH}$ and $-\mathrm{COOCH}_{3}$, the peak at $1639 \mathrm{~cm}^{-1}$ is due to $\mathrm{N}-\mathrm{H}$ bending vibration of amines, peak at $1124 \mathrm{~cm}^{-1}$ is assigned to alcoholic C-O stretching vibration. Peak at $931 \mathrm{~cm}^{-1}$ is for glycoside bonds in the polysaccharide structure ${ }^{22,23}$.

After the functionalization of biomaterial, the spectrum exhibits some changes in figure 2 . The intense sharp peak at $3409 \mathrm{~cm}^{-1}$ in the RKP shifted to $3393 \mathrm{~cm}^{-1}$ as a broad peak in AKP, that indicates the overlapping of hydroxyl groups with amine group in AKP. Thus, the broadband peaks confirmed the introduction of amine group onto the surface of funtionalised

biomaterial. Some peaks of RKP at $2926 \mathrm{~cm}^{-1}, 1639 \mathrm{~cm}^{-1}, 1124 \mathrm{~cm}^{-1}, 931 \mathrm{~cm}^{-1}$ are significantly reduced in AKP.

Elemental analysis shows the percentage composition of elements present in the Kush powder.Carbon and Nitrogen were found to be $41.27 \%$ and $1.13 \%$ in RKP where as $51.47 \%$ 
and $5.49 \%$ in AKP respectively. Increase in percentage of nitrogen after functionalization suggests the introduction of amine group in the Kush powder.

$\mathrm{pH}$ is one of the major factor which determines the removal capacity of different metal ions from aqueous solution by adsorption.Variation in $\mathrm{pH}$ could change the characteristics and availablity of metal ions in solution as well as the surface charge of biomaterial and degree of ionisation. At low pH, adsorption of Cd (II) and $\mathrm{Zn}$ (II) metal ions decreased which may be due to the increase in competition between metal ions and $\mathrm{H}^{+}$ions for the active sites on the biomaterial surface, where as adsorption increased with the increase in $\mathrm{pH}$ value of the solution, which may be due to lesser number of surface lagands with negative charges. Maximum adsorption of $\mathrm{Cd}$ (II) and $\mathrm{Zn}$ (II) were observed at $\mathrm{pH} 6$ as shown in figure 3.

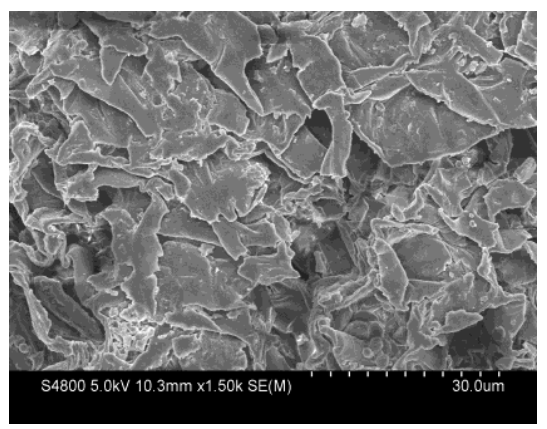

(1a)



(1c)

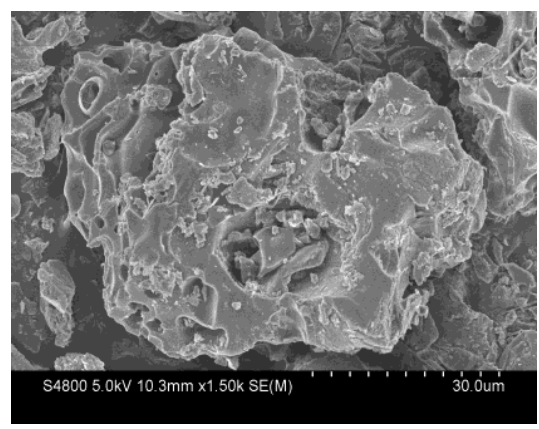

(1b)

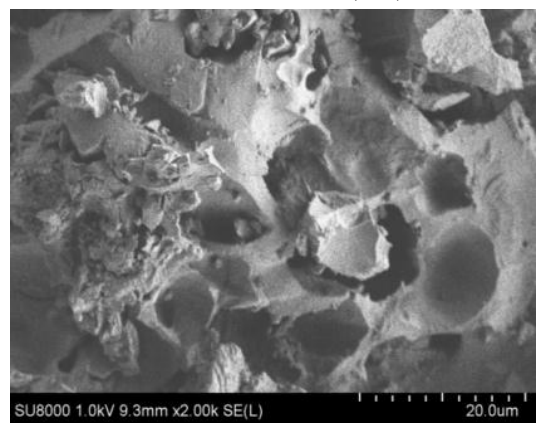

(1d)

Figure 1: Scanning electron microscope (SEM) photographs of (1a) RKP (1b) CKP and (1c, 1d) $A K P$.

Study of adsorption Isotherm helps to find the maximum adsorption capacity of the biomaterial. The maximum adsorption capacity of the functionalized biomaterial for Cd (II) and $\mathrm{Zn}$ (II) were investigated at the various concentrations from $25 \mathrm{mg} / \mathrm{L}$ to $800 \mathrm{mg} / \mathrm{L}$ of the respective metal ions.Figure 4 represents a plot of the adsorption amount $\left(\mathrm{q}_{\mathrm{e}} \mathrm{mg} / \mathrm{g}\right)$ versus the equilibrium metal ions concentration in the solution $\left(\mathrm{C}_{\mathrm{e}} \mathrm{mg} / \mathrm{L}\right)$. Equilibrium data were fitted as shown in figure 5 with the Langmuir adsorption Isotherm which is given by equation $2{ }^{17}$.

$$
\frac{C_{e}}{q_{e}}=\frac{1}{b q_{m}}+\frac{C_{e}}{q_{m}}
$$




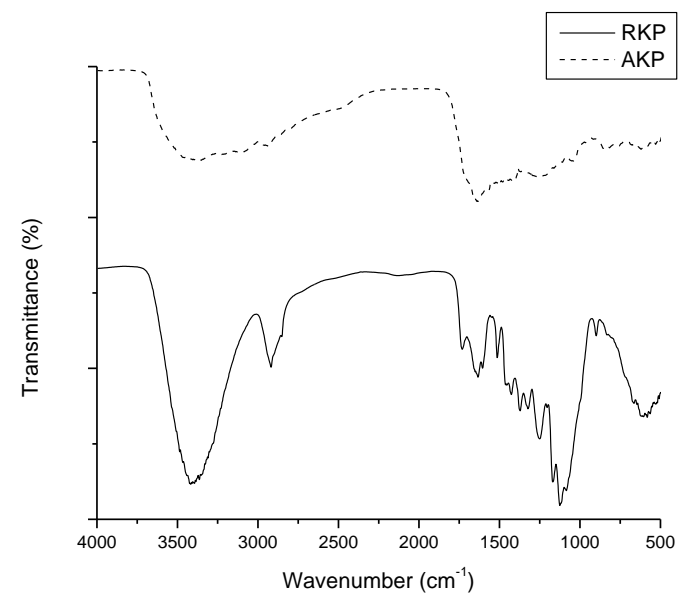

Figure 2: FTIR of (a) RKP and (b) AKP (after functionalization)

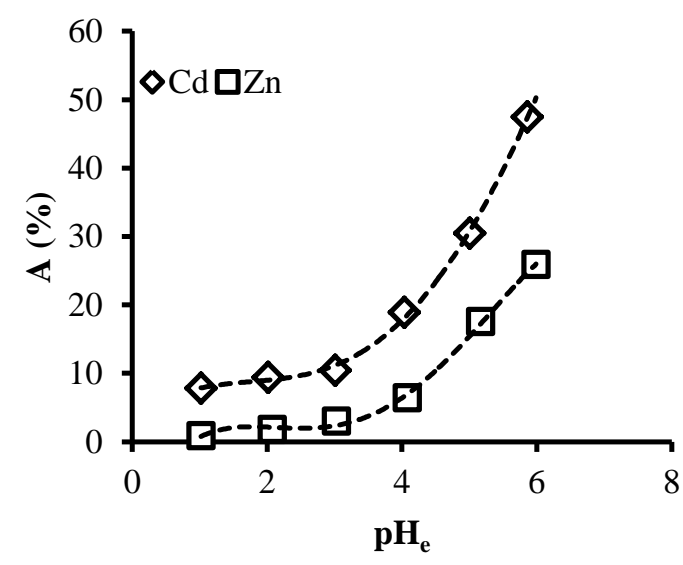

Figure 3: Effect of $p H$ in the adsorption of Cd (II and Zn (II) onto Aminated Kush powder.

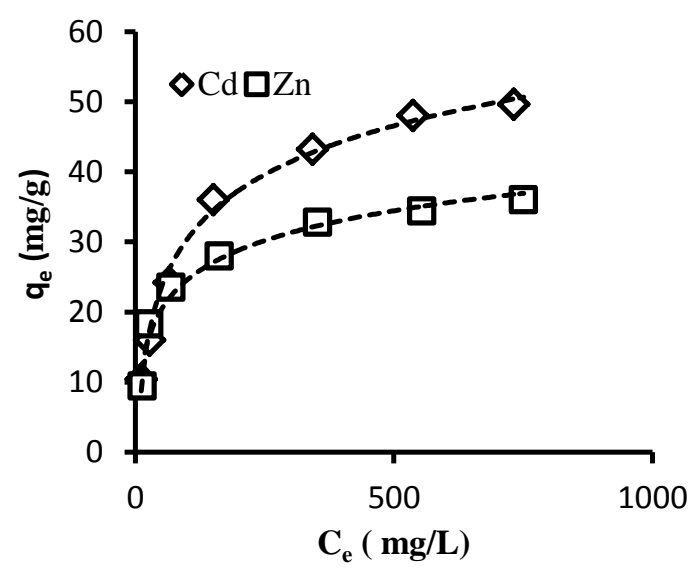

Figure 4: Adsorption isotherm for Cd (II) and Zn (II) onto Aminated Kush powder.

where, $\mathrm{q}_{\mathrm{m}}$ is the maximum amount of adsorption $(\mathrm{mg} / \mathrm{g}), \mathrm{b}$ is the adsorption equilibrium constant $(\mathrm{L} / \mathrm{g})$ and $\mathrm{C}_{\mathrm{e}}$ is the concentration $(\mathrm{mg} / \mathrm{L})$ of metal ions in solution at equlibrium.

The adsorption increase with increase in equilibrium concentration at low metal ions concentration and tend to approach constant value for each metal ions at their higher concentration, suggesting that these metal ions are adsorbed onto the biomaterial according to Langmuir adsorption. The adsorption of metal ions is eventually limited by the fixed numbers 
of active sites and a resulting plateau can be observed, which is well described by Langmuir parameter $\mathrm{q}_{\max }$. The maximum adsorption capacities evaluated in terms of $\mathrm{mg} / \mathrm{g}$ of biomaterial are $49.6 \mathrm{mg} / \mathrm{g}$ for $\mathrm{Cd}$ (II) and $36 \mathrm{mg} / \mathrm{g}$ for $\mathrm{Zn}$ (II) respectively, which is in close agreement with $\mathrm{q}_{\max }$ value obtained from the Langmuir plots given in Table 1. The experimental data are in good linear relationships, suggesting that the adsorption sites have equal affinities for the adsorbate molecules.



Figure 5: Langmuir plot for adsorption of Cd (II) and Zn (II) onto Aminated Kush powder.

Table 1: Langmuir adsorption isotherm model parameters and experimental $q_{\max }$

\begin{tabular}{|l|l|l|l|l|}
\hline Metal ions & Langmuir $q_{\max }(\mathrm{mg} / \mathrm{g})$ & $\begin{array}{c}\text { Experimental } q_{\max } \\
(\mathrm{mg} / \mathrm{g})\end{array}$ & $b(\mathrm{~L} / \mathrm{g})$ & \multicolumn{1}{|c|}{$R^{2}$} \\
\hline $\mathrm{Cd}$ & 55.56 & 49.60 & 0.014 & 0.998 \\
\hline$Z n$ & 38.42 & 36.00 & 0.023 & 0.998 \\
\hline
\end{tabular}

Batch adsorption experiments were carried out for different contact times with a fixed biomaterial dose of $25 \mathrm{mg}$ at their optimum $\mathrm{pH}$ 6. The equilibrium is reached between 150-180 minutes of adsorption for respective metal ions and reached a saturation level. As the contact time increased, the active sites on the adsorbents were filled and the adsorption rate became slower and reached the plateau as shown in figure 6.

Table 2: Sorption kinetics of pseudo second order for Metal ions onto AKP

\begin{tabular}{|l|l|l|}
\hline Metal ions & $R^{2}$ & $K_{2}(\mathrm{~g} / \mathrm{mg} / \mathrm{min})$ \\
\hline $\mathrm{Cd}$ & 0.998 & 0.0077 \\
\hline $\mathrm{Zn}$ & 0.998 & 0.0009 \\
\hline
\end{tabular}




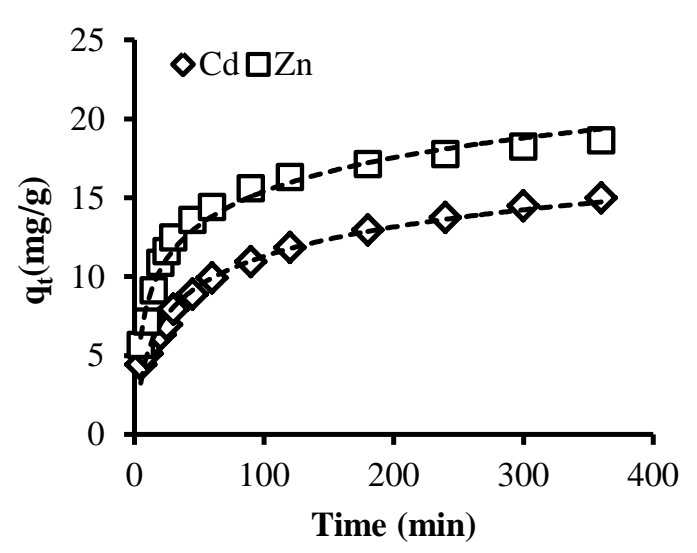

Figure 6: Adsorption kinetics of $C d$ (II) and Zn (II) onto Aminated Kush powder.

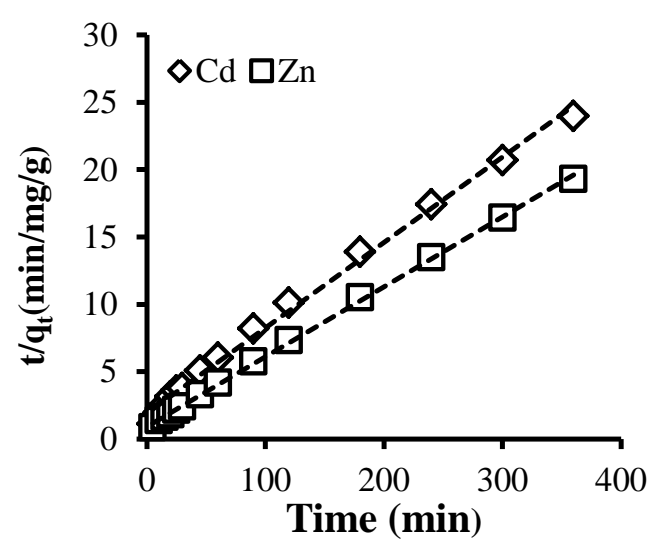

Figure 7: Pseudo second order kinetic model in the adsorption of $\mathrm{Cd}$ (II) and $\mathrm{Zn}$ (II) onto Aminated Kush powder.

Kinetic modeling of the data was studied using pseudo- second order rate equation, and its applicability was tested by linear plot of $t / q_{t}$ versus $t$, as shown in figure 7 .

The values of rate constant $\left(\mathrm{K}_{2}\right)$ for $\mathrm{Cd}$ (II) and $\mathrm{Zn}$ (II) are 0.0021 and 0.0028 , and correlation coefficient are 0.99 and 0.99 for the respective metal ions as given in table 2, which showed that the model can be applied for the entire adsorption process and confirm the chemisorption of respective metal ions onto the AKP.

\section{Conclusions}

AKP were prepared from RKP by treating with thionyl chloride followed by dimethylamine.Elemental analysis, SEM and FTIR analysis revealed the introduction of amine groups into the biomaterial which had shown good adsorption capacity for $\mathrm{Cd}$ (II) and $\mathrm{Zn}$ (II).The adsorption capacity increases with increase in $\mathrm{pH}$ upto their optimum $\mathrm{pH}$ value. The adsorption performances were fitted well with Langmuir model with correlation coefficient $\mathrm{R}^{2}$ of 0.99 and the rate of adsorption follows the pseudo second order kinetics. This concludes that the biomaterial with high metal binding capacity after functionalization may find potential application in wastewater treatment for the removal of heavy metal ions.

\section{Acknowoledgements}

Authors would like to thank Prof. Dr. P.K. Jha, Central Department of Botany, Tribhuvan University, Kathmandu and Dr. Antonio Masi and his team, Department of Biotechnology, Padova University, Italy for providing necessary laboratory facilities for the experimental work in Italy. Dr. Lok Kumar Shrestha, National Institute for Materials Science, Tsukuba, Japan and 
Dr. A.P. Yadav, Central Department of Chemistry, Tribhuvan University, Kirtipur are acknowledged for their help with SEM images.

\section{References}

1. K. Kadirvelu, K. Thamaraiselvi, C. Namasivayam, Bioresour. Technol., 2001a.76, 63-65.

2. C.J. Williiams, D. Aderhold, G.J. Edyvean, Water Res.1998, 32, 216-224.

3. C. Namasivayam, K. Ranganathan, Environ. Technol.1995, 16, 851-860.

4. K.N. Ghimire, K. Inoue, K. Ohto, T. Hayashida, Seperatiopn Science and Technology, 2007, 42:9, 2003-2018.

5. W.S. Wan Nagh, M.A.K.M. Hanifiah, Bioresourse Technology, 2008, 99, 3935-3948.

6. N.Ahalya, I.V.Ramachandran, H.D. Kanamadi, Res. J. Chem. Environ., 2003, 7, 71-78.

7. CSIRO, Activated Carbon, Welcome to Enecon's Website, May 2002, ftp:// enecon.com.au/activated.html.

8. F. V. Pereira,L.V.A.Gurgel,\&L.F. Gil, Journal of Hazardous Materials, 2010, 176, 856863.

9. M. S. Rahman \& M. R. Islam, Chemical Engineering Journal, 2009,149, 273-280.

10. W. S. W.Ngah \& M. A. K. M. Hanafiah, Bioresource Technology, 2008, 99, 3935-3948.

11. S.A. Ahmed, Carbohydrate Polymers, 2011, 83, 1470-1478.

12. S.R. Shukla, \& S. Pai, Bioresource Technology, 2005, 96, 1430-1438.

13. P. Miretzky, A. Fernandez Cirelli, Journal of Hazardous Materials, 2010,180, 1-19.

14. G. Sun, W. Shi, Ind. Eng. Chem., 1998, 37(4), 1324-1328.

15. S.Chen, Q.Yue, B. Gao, X.Xu, Journal of Collid and Interface Science, 2010, 349, 256-264.

16. N. Sankararamakrishnan, R. Sanghi, Cabohydrate Polymers, 2006, 66, 160-167.

17. S. Mandal, T. Padhi, R.K. Patel, Journal of Hazardous Materials, 2011, 192, 899-908.

18. P. L.Homagai, H.Paudyal and K. N. Ghimire. J. Nepal Chem. Soc., 23, 2008/2009, 102-105.

19. P.L. Homagai. K.N.Ghimire, K.Inoue, Biores. Technol., 2010, 101, 2067-2069.

20. Y.S.Ho, G. McKay, Process Biochem., 1999, 34, 451.

21. G. Moussavi, R. Khosravi, Journal of Hazardous Materials, 2010, 183, 724-730.

22. R.M. Silverstein, G.C. Bassler, T.C. Morril, Spectrometric Identification of Organic Compounds, John Willey and Sons: New York, 1981, 95.

23. R.L. Shriner, C.K.F. Hermann, T.C. Morrill, D.Y. Curtin, R.C. Fuson, The Systematic Identification of Organic Compounds, Seventh ed. Wiley, New York, 1998, p. 324. 